\title{
A INCLUSÃO ESCOLAR E O ALUNO COM SÍNDROME DE DOWN: AS ADAPTAÇÕES CURRICULARES E A AVALIAÇÃO DA APRENDIZAGEM
}

\author{
SOUSA, Neide Maria Fernandes Rodrigues ${ }^{1 *}$; NASCIMENTO, Deisiane Aviz ${ }^{1 * *}$ \\ ${ }^{1}$ Universidade Federal do Pará \\ neylla64@gmail.com* \\ deisi.aviz@gmail.com**
}

\section{RESUMO}

A pesquisa tem o objetivo de compreender a percepção dos professores sobre a inclusão escolar de alunos com Síndrome de Down no que se refere às adaptações curriculares e o processo avaliativo. Adotou-se uma abordagem qualitativa do tipo estudo de caso. Participaram da pesquisa nove professores da sala regular com aluno com Síndrome de Down e uma professora da sala de recurso multifuncional. A pesquisa foi realizada em uma escola municipal de ensino fundamental do 60 ao 9o ano. Nos resultados, cinco professores indicaram fazer adaptações de conteúdo e atividades, e quatro indicaram não fazer adaptações; quanto à avaliação, quatro professores indicaram fazer provas adaptadas, três avaliavam as atividades cotidianas da aluna e dois não desenvolviam avaliação. Conclui-se que a inclusão, na realidade educacional, é um processo com avanços e retrocessos, precisando de uma política com ações mais direcionadas às situações do contexto escolar.

PALAVRAS-CHAVE: Inclusão escolar. Síndrome de Down. Adaptações curriculares. Avaliação da aprendizagem.

\section{SCHOOL INCLUSION AND THE STUDENT WITH DOWN SYNDROME: CURRICULAR ADAPTATIONS AND EVALUATION OF LEARNING}

\begin{abstract}
The research has the objective of understanding the perception of the teachers about the inclusion of students with Down Syndrome in relation to curricular adaptations and the evaluation process. A qualitative case-study approach was adopted. Nine teachers of the regular classroom with a Down Syndrome student and one teacher of multifunctional resource rooms participated of the research. The research was carried out in a Municipal Primary School of the 6th to the 9th grade. In the results, situations of the school context.

KEYWORDS: School inclusion. Down Syndrome. Curricular adaptations. Evaluation of learning.

\section{LA INCLUSIÓN ESCOLAR Y EL ALUMNO CON SÍNDROME DE DOWN: LAS ADAPTACIONES CURRICULARES Y LA EVALUACIÓN DEL APRENDIZAJE}

five teachers indicated to make adaptations of contents and activities, four teachers did not indicate to make adaptations; about the evaluation, four teachers indicated to make adapted tests, three teachers evaluate the everyday activities of the student and two do not develop the evaluation. It was concluded which the inclusion on the educational reality is a process with advances and setbacks, needing of a policy with actions more directed to the

\section{RESUMEN}

La investigación tiene el objetivo de comprender la percepción de los profesores sobre la inclusión escolar de alumnos con Síndrome de Down en lo que se refiere a las adaptaciones curriculares y el proceso de evaluación. Se adoptó un enfoque cualitativo, del tipo estudio de caso. Participaron de la investigación nueve profesores del aula regular con alumno con Síndrome de Down y una profesora del aula de recursos multifuncional. La investigación fue realizada en una escuela municipal de enseñanza fundamental del 60 al 9o año. En los resultados, cinco profesores indicaron hacer adaptaciones de contenido y actividades, y cuatro indicaron no hacer adaptaciones; en cuanto a la evaluación, cuatro profesores indicaron hacer exámenes adaptados, tres evaluaban las actividades cotidianas de la alumna y dos no desarrollaban evaluación. Se concluye que la inclusión en la realidad educativa es un proceso con avances y retrocesos, necesitando una política con acciones más orientadas a las situaciones del contexto escolar.

PALABRAS CLAVE: Inclusión escolar. Síndrome de Down. Adaptaciones curriculares. Evaluación del aprendizaje.

Educação \& Formação, Fortaleza, v. 3, n. 9, p. 121-140, set./dez. 2018

DOI: https://doi.org/10.25053/redufor.v3i9.859

http://seer.uece.br/redufor 


\section{INTRODUÇÃO}

A inclusão de alunos com deficiência nas classes regulares de ensino tem sido um dos principais focos de discussões e pesquisas no cenário educacional brasileiro. Os desafios de uma educação inclusiva estão relacionados à concretização de um ensino de qualidade para todos os alunos, na busca do acesso e permanência e de respostas educativas com modificações no processar rotineiro da escola. Um tipo de aluno atendido na perspectiva da inclusão escolar é o estudante com Síndrome de Down (SD), haja vista que sua escolarização envolve ações complexas com a necessidade de adaptações curriculares (FERRAZ; ARAÚJO; CARREIRO, 2010; MENDES, 2006; SOUSA, 2007).

A inclusão escolar no Brasil teve seu início na década de 90 do século passado e tem como princípio o direito à diferença, na perspectiva de que todas as crianças devem aprender juntas. A construção de um sistema educacional inclusivo tomou impulso a partir de alguns aportes legais e políticos, como a Constituição Brasileira de 1988, a Declaração Mundial sobre Educação para Todos e a Declaração Mundial de Salamanca (BRASIL, 1997; UNESCO, 1990).

A Política Nacional de Educação Especial, na concepção da educação inclusiva apresentada em 2008, busca integrar a proposta pedagógica da escola regular com a expectativa de garantir a inclusão escolar de alunos com deficiência, transtornos globais do desenvolvimento e altas habilidades no ensino regular, garantindo direito à aprendizagem, participação e continuação nos níveis mais elevados de ensino (BRASIL, 2008). Um tipo de aluno atendido nessa proposta é o aluno com SD. A SD é um acidente genético que acontece no par do cromossomo 21, com a presença de um cromossomo extra. A pessoa com SD apresenta atraso no seu desenvolvimento funcional, físico e intelectual (PACHECO; OLIVEIRA, 2011).

Na pesquisa, buscamos compreender aspectos da inclusão do estudante com SD a partir da percepção de professores. Para direcionar o caráter investigativo da pesquisa, as seguintes questões orientaram o trabalho: como o professor percebe a inclusão escolar do discente com SD? Como ocorrem as adaptações curriculares e a avaliação da aprendizagem do educando com SD? Na tentativa de responder às questões norteadoras, estabelecemos como objetivo compreender a percepção dos professores acerca da inclusão escolar de alunos com SD referentes às adaptações curriculares e ao processo avaliativo do discente com SD. Na incursão

Educação \& Formação, Fortaleza, v. 3, n. 9, p. 121-140, set./dez. 2018 DOI: https://doi.org/10.25053/redufor.v3i9.859 
teórica e conceitual, fizemos uma breve discussão sobre esse alunado, a inclusão escolar e as adaptações curriculares.

\section{O ALUNO COM SÍNDROME DE DOWN (SD) E A INCLUSÃO ESCOLAR}

A SD ou trissomia 21 é uma condição genética, um desequilíbrio na formação cromossômica, com a presença de um cromossomo a mais no par 21. As pessoas com SD têm 47 cromossomos, em vez de 46. Algumas características típicas são o desenvolvimento motor e cognitivo mais lento, deficiência intelectual, rosto com perfil achatado, pálpebras com inclinação para cima, orelhas pequenas, arredondadas e displásicas, além de alterações na linguagem, motricidade e interação. Essas condições manifestam-se de maneira distinta entre os sujeitos. $O$ aspecto psicossocial também é importante na avaliação da pessoa com SD. A evolução desta varia de acordo com a característica individual e o ambiente, sem um tempo fixo para a construção da aprendizagem. A construção das habilidades (cognitivas e sociais) e a superação das limitações da criança com SD dependem de um ambiente estimulante e favorável (CASTRO; PIMENTEL, 2009; VOIVODIC, 2005).

Estudantes com SD têm mais possibilidades de desenvolvimento quando percebidos como pessoas capazes de receberem estimulação pedagógica adequada; para isso, é necessário que o sistema de ensino considere-o detentor de potenciais de aprendizagens, de características próprias e de repertório de comportamentos diferenciados que devem ser superestimados e aprimorados pelo próprio processo educacional. As características da escola e o tipo de ensino disponibilizado podem originalizar ou intensificar as dificuldades de aprendizagem (FONSECA, 1995; MARCHESI, 2004; OLIVEIRA; SILVA, 2010).

O contexto familiar é outra dimensão importante na educação da pessoa com SD, uma vez que a interação positiva entre pais e filhos promove efeitos relevantes para o progresso das áreas cognitivas, linguísticas e socioemocionais da criança com SD. Para Palacios (1995), na interação com adultos e colegas mais desenvolvidos, a criança recebe instrumentos e estratégias psicológicas aprimoradas por meio da internalização que vai proporcionar aprendizagens significativas.

Educação \& Formação, Fortaleza, v. 3, n. 9, p. 121-140, set./dez. 2018 
Assim, a SD não deve se constituir num entrave à garantia de oportunidades educacionais. É importante a superação das dificuldades associadas às características biológicas da deficiência, levando em consideração seus ritmos de aprendizagem e respeitadas as caraterísticas peculiares.

\section{ASPECTOS DA INCLUSÃo ESCOLAR: AS ADAPTAÇÕES CURRICULARES E A AVALIAÇÃO DA APRENDIZAGEM}

A educação inclusiva é um paradigma educacional fundamentado na concepção de direitos humanos, relacionando igualdade e diferença como valores indissociáveis. Uma ação de cunho político, cultural, social e pedagógico desenvolvida em defesa dos direitos de todos os alunos estudarem juntos sem quaisquer tipos de discriminação e com as mesmas oportunidades de participação e aprendizagem (BRASIL, 2008).

A inclusão escolar tem como proposta uma educação de qualidade para todos com uma reestruturação do sistema escolar. Nessa perspectiva, as modificações envolvem uma política educacional eficaz; o projeto pedagógico; uma flexibilidade organizacional. Além de provisão de recursos suplementares e complementares; acessibilidade a todos os ambientes físicos; parceria com os pais; gestão mais democrática; aproveitamento máximo dos recursos materiais e humanos; identificação e avaliação das necessidades educativas especiais; currículos abertos e flexíveis com adaptações curriculares individualizadas e com modificações nos métodos, técnicas, agrupamentos e formas de avaliação; formação inicial e continuada de professores e intensificação de ações voltadas para o atendimento na classe comum. A inclusão escolar é um desafio constante no qual se questionam valores, crenças, concepções, normas, resistências e atitudes (MARCHESI, 2004; SOUSA, 2015).

Na escola inclusiva, é imprescindível que crianças aprendam juntas, independentemente de dificuldades ou diferenças, com o envolvimento entre todos, na promoção de sentimentos de respeito, comunicação, confiança, entre outras. Para responder às múltiplas necessidades de seus alunos, a escola deve se organizar de acordo com os ritmos de aprendizagem, através de apropriações curriculares, alterações organizacionais e adoção estratégica de ensino diferenciado (FERRAZ; ARAÚJO; CARREIRO, 2010; MANTOAN, 2004).

Educação \& Formação, Fortaleza, v. 3, n. 9, p. 121-140, set./dez. 2018 
As adaptações curriculares são estratégias da atuação docente que possibilitam ajustar ações de ensino de acordo com as especificidades de aprendizagem dos alunos, constituindo-se em possibilidades diferenciadas de ensinar. Para Heredero (2010), as necessidades de alunos com deficiências requerem respostas educacionais adequadas com flexibilizações curriculares. Cada aluno tem seu próprio tempo de aprendizagem. Diante disso, é preciso reconhecer e respeitar as individualidades, proporcionando ao sujeito com deficiência aprender os mesmos conteúdos, mas com adequações necessárias do currículo, que podem ser referentes a agrupamentos e novas organizações temporais.

As adaptações classificam-se em três níveis: no âmbito do projeto pedagógico e seu currículo escolar; no currículo desenvolvido em sala de aula; e no nível individual para cada discente. As adaptações curriculares individuais são ações significativas com modificações nas metodologias, objetivos, conteúdos e critérios de avaliação. Nessa, é considerada a avaliação inicial do aluno, sendo construída entre a equipe multidisciplinar, especialistas e professores (BLANCO, 2004).

Construir um currículo que atenda à pessoa com SD é levar em consideração a identidade e suas vivências cotidianas, potencializando seu aprender. No contexto da sala de aula, um dos elementos de adaptações curriculares individuais é o processo de avaliação diferenciado que possa se adequar às capacidades e possibilidades do aluno com deficiência.

\subsection{Avaliação da aprendizagem e o aluno com SD}

A avaliação da aprendizagem de alunos com SD se constitui uma etapa primordial, pois permite verificar sua aprendizagem, contribuir para a compreensão da origem e manifestação das dificuldades e possibilitar a elaboração estratégica de ações pedagógicas mais adequadas para promoção e superação das barreiras que interferem no processo de ensino-aprendizagem.

Segundo Luckesi (2008), a avaliação da aprendizagem deve servir de suporte no processo de adoção de atitudes metodológicas mais adequadas para se alcançar os objetivos, representando um meio que fortaleça o crescimento do educando. Avaliação e planejamento estão articulados, representando um mecanismo subsidiário de planejamento e execução. Desse

Educação \& Formação, Fortaleza, v. 3, n. 9, p. 121-140, set./dez. 2018

DOI: https://doi.org/10.25053/redufor.v3i9.859

http://seer.uece.br/redufor 
modo, a prática avaliativa tem sentido quando serve de diagnóstico numa perspectiva de melhoria dos resultados.

A avaliação é uma das proposições de adaptações curriculares. A avaliação é um processo complexo em decorrência das especificidades de cada estudante e das características típicas do educando com deficiência. A avaliação processual e intencional de alunos com deficiência intelectual demonstra aquilo que já aprenderam e indica as formas como aprendem, colaborando no desvelamento do seu potencial e possibilidades de práticas favorecedoras de aprendizagem (OLIVEIRA; CAMPOS, 2005; OLIVEIRA; PLETSCH, 2014; VALENTIM, 2011).

Hoffmann $(2009,2001)$ afirma que o processo avaliativo está centrado nos aspectos educacionais, e não apenas no entendimento imediato dos conteúdos; questiona a ideia de terminalidade, de finalização e de atribuição de notas ou conceitos e cálculo de médias no processo avaliativo. Para a autora, a ação avaliativa precisa ser vista como mediações que visem encorajar a reorganização do saber, propiciando ações, movimentos e provocações que gerem uma troca intelectual de conhecimentos entre professores e alunos, resultando em um processo reflexivo e desafiador. Os estudantes estão em evolução, em diferentes ritmos e caminhos singulares, e o professor deve estimulá-los a progredir sempre.

De acordo com as Diretrizes Nacionais para a Educação Especial na Educação Básica, as escolas devem adotar procedimentos de avaliação pedagógica alternativa que vise ampliar as possibilidades de inclusão social e produtiva da pessoa com deficiência (BRASIL, 2010). As intervenções escolares e a avaliação adequada às especificidades dos aprendizes com SD, segundo Pimentel (2012), permitem estimular suas potencialidades. Nessa perspectiva, o aluno com SD tem capacidade, assim como os demais alunos, de participar do processo de avaliação.

\section{MÉTODO}

\subsection{Tipo de pesquisa}

No presente estudo, adotou-se a abordagem qualitativa, do tipo estudo de caso, que consiste no estudo de um caso particular, sendo representativo de situações análogas (SEVERINO, 2007).

Educação \& Formação, Fortaleza, v. 3, n. 9, p. 121-140, set./dez. 2018

DOI: https://doi.org/10.25053/redufor.v3i9.859

http://seer.uece.br/redufor 


\subsection{Lócus de estudo}

A pesquisa foi realizada em uma escola municipal de ensino fundamental do 60 ao 9 은 ano no município de Augusto Corrêa, Pará. A escola tem 1.697 alunos e sua estrutura física é composta por uma sala da direção, coordenação, secretaria, biblioteca, sala de informática, sala dos professores, sala de recurso multifuncional, onde é realizado o atendimento educacional especializado, salas de aulas, cozinha e refeitório. O levantamento foi realizado em uma turma regular inclusiva com uma aluna com SD que estava no 90 ano do ensino fundamental, tinha 19 anos e frequentava a escola desde 2014.

\subsection{Sujeitos}

Participaram da pesquisa nove professores da sala regular com aluno com SD e uma professora da sala de recurso multifuncional. Não participou da pesquisa a aluna com SD que estudava em uma sala regular desde 2014, a qual tinha então 19 anos e estava no 9o ano.

\subsection{Instrumentos e procedimentos de levantamento}

Inicialmente solicitamos autorização da escola e dos participantes para o levantamento dos dados. Utilizamos como instrumento a entrevista semiestruturada com dois roteiros - um direcionado para os professores da sala regular e outro para a professora da sala de recursos. 0 roteiro de entrevista direcionado aos professores da sala regular tinha questões referentes à percepção da inclusão na escola; experiência de trabalho na área de educação especial; adaptações curriculares na sala de aula com o foco nas práticas pedagógicas, nas avaliações e nas dificuldades de trabalho com a discente. O roteiro direcionado à professora da sala de recurso multifuncional tinha questões referentes à percepção sobre a inclusão e o processo avaliativo, as atividades pedagógicas da sala de recurso multifuncional e a relação entre sala de recurso multifuncional e sala regular.

Educação \& Formação, Fortaleza, v. 3, n. 9, p. 121-140, set./dez. 2018 DOI: https://doi.org/10.25053/redufor.v3i9.859 


\subsection{Procedimento de análise}

Para a organização e interpretação dos dados, utilizamos a análise de conteúdo na perspectiva de Bardin (2011), estruturada em três etapas: pré-análise, exploração de material e tratamento de dados. Na pré-análise, fizemos a transcrição e leitura flutuante. Na exploração do material, definimos as categorias, possibilitando a fase descritiva e analítica da pesquisa. E, por último, no tratamento dos resultados obtidos, realizamos as interpretações inferentes das informações adquiridas, através de análises críticas e reflexivas.

\section{RESULTADOS E DISCUSSÕES}

Nos resultados, inicialmente indicamos o perfil dos sujeitos - professores da sala regular e professora da sala de recurso multifuncional. Em seguida, apresentamos as categorias temáticas encontradas no levantamento com as discussões. As categorias temáticas ou unidades de sentido foram: a) Inclusão no contexto escolar; b) Adaptações curriculares: conteúdos, atividades e dificuldades encontradas; c) Avaliação: instrumentos, critérios norteadores e possibilidades de mudanças.

\subsection{Perfil dos sujeitos}

- Professores da sala regular - Dos nove professores entrevistados, cinco eram do sexo masculino e quatro, do sexo feminino. Apenas um profissional (da sala de recurso multifuncional) tinha formação na área de educação especial. Os outros professores apresentaram experiência docente entre cinco meses e 19 anos. Sobre a experiência com a aluna com SD: seis docentes indicaram ser a primeira experiência, e três apontaram que haviam tido experiência de trabalho com a aluna anteriormente;

- Professora da sala de recurso multifuncional - Especialista em atendimento especializado educacional. Trabalhava havia cinco anos na escola e já tinha experiência com a aluna havia quatro anos.

Educação \& Formação, Fortaleza, v. 3, n. 9, p. 121-140, set./dez. 2018 
No perfil, observamos a pouca capacitação dos professores na área de educação especial/inclusiva. Apesar dos dispositivos legais, como a Resolução n. 2, do Conselho Nacional de Educação e do Conselho de Educação Básica (CNE/CEB), de 11 de setembro de 2001, e a Lei de Diretrizes e Bases da Educação Nacional, Lei n. 9.394/1996, que estabelecem normas para a capacitação e especialização de professores no ensino regular, a realidade educacional indica que as políticas públicas na área são deficitárias, o que pode provocar dificuldades na prática pedagógica, na aprendizagem e no desenvolvimento dos educandos.

No atendimento ao alunado da educação especial, na perspectiva da inclusão escolar, a formação de professores (inicial e continuada) é essencial. A atuação docente tem a capacidade de promover aos alunos, sejam esses deficientes ou não, altos níveis de aprendizagem, sendo imprescindível na inclusão escolar uma política de formação de professores eficiente, com recursos humanos capacitados e em condições de trabalho. Desse modo, são necessários mecanismos de apoio que garantam a consolidação e o aprofundamento das potencialidades profissionais, reconhecimento e formação inicial e continuada, o que requer do professor disponibilidade para aprender e do sistema de ensino prover essa possibilidade. Sob esse viés, cabe ao Estado o controle dos recursos financeiros, decisões políticas e responsabilidade pela oferta de um ensino de qualidade (DENARI, 2006; FREITAS, 2006; MENDES, 2004; TARDIF, 2002).

\subsection{Inclusão no contexto escolar}

Do total de nove professores da sala regular, seis (de Português, Ciências, Geografia, Artes, Estudos Amazônicos e Inglês) afirmaram que a inclusão acontecia de forma precária. Esses docentes disseram que os estudantes com deficiência eram incluídos e que os pais estavam mais envolvidos, no entanto apontaram as dificuldades da inclusão, como: falta de formação na área e suporte aos professores, resultando em barreiras na escolarização deles.

Três educadores (de Matemática, História e Ensino Religioso) informaram que a inclusão não estava acontecendo, pois esses discentes eram excluídos, devido ao fato de não conseguirem obter os mesmos rendimentos dos ditos normais, não acompanharem os conteúdos propostos e não disporem da atenção necessária, visto que eram comprometidos pela fragilidade da formação dos educadores. Em seguida, as narrativas de dois professores: 
Precisa melhorar em muitos aspectos, principalmente em mais investimentos em formações para os professores. (Professor de Ciências).

A inclusão não está acontecendo; os alunos com deficiência só estão inseridos, mas não interagem como deveriam, até mesmo porque muitos professores não têm formações voltadas para essa área. Diante disso, não estão preparados para trabalhar com esse público. (Professor de História).

Segundo Pletsch (2011), apesar de um aumento no conjunto de aportes legais e políticos direcionados à inclusão escolar, não se apresentam condições efetivas para que de fato ocorra a inclusão, o que leva a responsabilizar o sujeito pelo seu "sucesso" ou "fracasso" na escola.

Para a professora da sala de recurso multifuncional, a inclusão ocorre de forma lenta, precisando melhorar. Ela afirmou que os alunos estão inseridos e interagindo como qualquer outra pessoa. Os problemas existentes não estão associados às limitações da deficiência, mas ao contexto em que estão introduzidos e as políticas mal planejadas. Segundo ela, para que a inclusão aconteça, são necessárias reformas e mudanças de concepções. Conforme a narrativa da professora:

[...] infelizmente alguns profissionais enxergam apenas as dificuldades, não apresentam soluções, muito menos se dispõem a contribuir com este processo, esperam receitas prontas e acabadas, só para executarem! Para que de fato aconteça, é necessário, além de reformas estruturais, currículo, entre outras mudanças de concepções de alguns professores. (Professora da sala de recurso multifuncional).

No cotidiano escolar, a inclusão requer uma reflexão de valores e práticas sobre diferenças, deficiência e políticas públicas eficientes. Um processo que não acontece de maneira repentina e aleatória, cada instituição tem seu próprio ritmo de transformação. Nesse sentido, as escolas vivenciarão barreiras diferentes no tocante à introdução dos ideais inclusivos. Ademais, a inclusão é uma jornada com propósito, a qual envolve mudanças e reestruturações das escolas como um todo (MARCHESI, 2004; MITTLER, 2003).

\subsection{As adaptações curriculares: conteúdos, atividades e dificuldades encontradas}

Os dados revelam que, do total de nove professores da sala regular, cinco docentes informaram fazer adaptações do conteúdo e das atividades, mas apresentaram dificuldades. As adequações mais citadas foram: atividade de cobrir, desenho para colorir, recorte e colagem. A narrativa da professora de Português ilustra a dificuldade de adaptação curricular: "Faço

Educação \& Formação, Fortaleza, v. 3, n. 9, p. 121-140, set./dez. 2018

DOI: https://doi.org/10.25053/redufor.v3i9.859

http://seer.uece.br/redufor 
atividades extras de cobrir e pintar. Tenho dificuldade, não tenho formação nem especialização. Ela não é alfabetizada, faz riscos no caderno! Me sinto impotente, limitada! Busco pesquisar na internet".

Quatro professores indicaram não fazer nenhum tipo de adaptação no conteúdo em decorrência das dificuldades encontradas. Entre os obstáculos informados pelos docentes, estavam: a aluna não é alfabetizada; não consegue acompanhar os conteúdos propostos; não faz atividades; tem problemas para receber regras. Comentaram que suas dificuldades estavam relacionadas ao fato de não possuírem formação e de a faculdade não os ter preparado. A narrativa do professor de Matemática retrata essa ideia: “É muito complexo trabalhar com a aluna, pois não sabe ler e escrever e não conhece os numerais. Não consigo adaptar as atividades nem trabalhar com a discente".

Alguns professores da sala regular informaram que procuravam a docente da sala de recurso multifuncional para solicitar informações sobre adaptações e esclarecer suas dúvidas. Os professores da sala regular indicaram apresentar dificuldades em trabalhar com a aluna. Nas narrativas, expressaram diversas razões: a discente não é alfabetizada; faz apenas riscos; rejeita executar atividades propostas; permanece pouco tempo em sala de aula e sai constantemente da sala; tem muitas faltas; além do número elevado de estudantes em sala, o que torna difícil dar atenção para a discente com SD.

Para esses professores, em virtude de a discente não ter adquirido as habilidades de leitura e escrita, o ensino era restrito, constituindo um impasse que intervém na promoção de atividades. Em consequência da complexidade dos conteúdos, as adaptações curriculares tornavam-se quase inexistentes devido à aluna não conseguir desenvolver o próprio nome, resultando em atividades básicas de pintura, recorte e colagem, que, muitas vezes, são desconectadas do conteúdo trabalhado com os aprendizes sem deficiência.

Uma das barreiras para a prática escolar inclusiva para os alunos-alvo da educação especial é a falta de flexibilização curricular. O currículo deve ser aberto, flexível, dinâmico e passível de modificações, colocando em foco as especificidades e o desenvolvimento dos estudantes. Com base na resolução n. 1 CNE/CEB, de 15 de maio de 2009, as adaptações curriculares devem considerar o sentido básico e instrumental dos conteúdos, metodologias de ensino e recursos didáticos diferenciados (BRASIL, 2009).

Educação \& Formação, Fortaleza, v. 3, n. 9, p. 121-140, set./dez. 2018 
Nesse sentido, o processo de adaptação curricular está associado ao atendimento educacional especializado, que tem a função de complementar e oferecer serviços, recursos de acessibilidade e estratégias que eliminem as barreiras de participação e aprendizagem. As adaptações de conteúdos e atividades são alternativas que visam ao ensino-aprendizagem do aluno com SD, no entanto devem ser conectadas com os demais, para não se restringir a conteúdos sem significado e intencionalidade.

Para Pletsch et al. (2017), em uma perspectiva inclusiva, a diversificação curricular na escola é central para o público-alvo da educação especial. Essa diferenciação pode ocorrer em vários aspectos, dentre esses, nos modos e estratégias organizadas pelos professores no trabalho pedagógico para atender à heterogeneidade da turma e em específico às necessidades educativas dos alunos.

\subsection{Avaliação: instrumentos, critérios norteadores e possibilidades de mudanças}

Do total de nove professores da sala regular, quatro docentes informaram introduzir provas adaptadas. Os instrumentos avaliativos mais citados foram: trabalhos, atividades de classe e testes adaptados. Três professores disseram que não realizavam provas, uma vez que sua avaliação era processual, levando-se em conta o desempenho diário da aluna com SD e sua participação em sala de aula; nessa utilizavam a observação das atividades da estudante com SD. Dois docentes informaram não desenvolver avaliação para a aluna com SD: eles atribuíam nota mínima (cinco pontos); disseram que as dificuldades existentes interferiam na prática avaliativa. Vejamos a fala de um dos entrevistados: "[...] tenho dificuldades em desenvolver atividades que visem avaliar seu desempenho escolar. É complicado instrumentalizar um teste para a aluna; trabalhar conteúdos de História com ela é muito difícil, primeiramente porque ela não sabe ler nem escrever, faz só riscos!" (Professor de História).

Na prática de avaliar a aluna, cada educador dispunha de critérios próprios, porém todos eram orientados a levar em consideração a participação, interação, presença em sala, desenvolvimento diário, etc. Destacamos a narrativa de um professor: "Somos orientados a dar nota mínima, que é cinco pontos, pois não podemos reprovar a aluna" (Professor de História).

Educação \& Formação, Fortaleza, v. 3, n. 9, p. 121-140, set./dez. 2018

DOI: https://doi.org/10.25053/redufor.v3i9.859

http://seer.uece.br/redufor 
Os professores adotavam metodologias avaliativas distintas. Cinco informaram que procuravam a professora da sala de recurso multifuncional para solicitar orientações. Um docente disse que reforçava o conteúdo e exibia vídeos. Uma professora comunicou que procurava ajuda dos pais da aluna. Um docente disse que não fazia nada e lhe dava nota mínima. Outra profissional disse que não sabia o que fazer.

Ensino-aprendizagem e avaliação são processos indissociáveis, assim não avaliar e conceder nota mínima não subsidia os processos de aprendizagem/desenvolvimento da aluna com SD. Concordamos com Hoffmann (2009) ao afirmar que a avaliação da aprendizagem escolar auxilia a regular a aprendizagem e a repensar as formas de ensino. Para a autora, promover de maneira automática, sem reflexão sobre a prática escolar, há o risco de maximizar o abandono às crianças.

A professora da sala de recurso multifuncional informou que o atendimento era realizado em articulação com os conteúdos trabalhados em sala regular, com adaptações, atividades diferenciadas com suporte de materiais pedagógicos, auxílio em trabalhos, entre outras. No caso da aluna com SD, as atividades eram voltadas para a alfabetização. Narrou que a estudante faltava ao atendimento e só comparecia sala de recurso multifuncional quando não queria permanecer na sala de aula. Segundo ela, a discente geralmente não fazia provas; às vezes, alguns professores levavam testes adaptados com atividades básicas de pintura, recorte e colagem, etc. Examinemos o que disse a docente da sala de recurso multifuncional:

\footnotetext{
Em dias de prova, os professores da sala de aula direcionam os alunos com deficiência para a sala de recurso multifuncional para receberem nosso auxílio; muitos chegam com os testes adaptados e outros para nós adaptarmos. O problema é que encontramos dificuldade em adaptar os testes, pois somos formados em Pedagogia, não dominamos conteúdos de Matemática, Inglês, História, entre outras. [...] devido à demanda de aluno ser elevada para a quantidade de professores da sala de recurso, infelizmente nem todos os alunos recebem auxílio, priorizamos aqueles que frequentam o atendimento!
}

Os dados sugerem que o processo avaliativo da aluna com SD era frágil, em decorrência das dificuldades apresentadas pelos professores em direcionar uma avaliação que contemplasse suas particularidades. Cada professor trabalhava de maneira distinta: uns adotavam o aspecto quantitativo, com aferição de notas por meio de adaptação de atividades; outros adotavam os requisitos qualitativos, em que a avaliação é vista como processual, por meio de interação, socialização, participação em sala, etc.; há alguns que adotavam tanto o qualitativo quanto o 
quantitativo, introduzindo testes adaptados e levando em consideração suas interações em classe; e também existiam aqueles que concediam nota mínima sem realizar avaliação.

Entendemos que a avaliação da aluna com SD precisa ser ressignificada, com reflexões sobre diferenças sociais e desenvolvimento/aprendizado de pessoas com SD, para que o processo avaliativo subsidie ações que visem de fato à promoção da aprendizagem e ao desenvolvimento da estudante. A avaliação e ensino/aprendizado constituem unidades indissolúveis; a avaliação dá suporte para reencaminhar a atividade docente e proporcionar informações úteis para a melhoria e eficácia das ações estratégicas de ensino, favorecendo o desenvolvimento de um aprendizado mais significativo (COLL; MARTíN; ONRUBIA, 2004; LUCKESI, 2008).

Na organização do processo avaliativo na inclusão escolar, são necessárias, entre outras reflexões sobre diferenças e desigualdades, identificação das necessidades do aluno com SD e ações direcionadas ao desenvolvimento/aprendizado do discente. Souza e Macedo (2012) afirmam que a avaliação da aprendizagem é uma ação que facilita o desenvolvimento educativo do aluno e possibilita a inclusão. Na mesma direção, Christofari (2012) assinala que na inclusão escolar a avaliação da aprendizagem deve ser vista como um instrumento de construção e reconstrução de relações, uma maneira de recriar estratégias pedagógicas direcionadas às especificidades dos alunos.

A avaliação, em uma perspectiva classificatória e tradicional, estimulava a competição, a classificação entre bons e maus, reforçava a exclusão, igualando a todos e ignorando as diferenças. O processo avaliativo fundamentado em uma concepção dinâmica, formativa e processual articulada à proposta inclusiva proporciona o encaminhamento do trabalho pedagógico para a superação de antigos estigmas. Nesse sentido, a avaliação de discentes com deficiência exige o rompimento de práticas tradicionais de avaliação da aprendizagem escolar (HOFFMANN, 2009; ROPOLI et al., 2010; TRENTIN, 2013; VALENTIM; OLIVEIRA, 2013).

As ações avaliativas muitas vezes se distanciam do seu sentido de instrumento auxiliador de estratégias de ensino, limitando-se à apuração de resultados em uma perspectiva de promoção. A avaliação necessita submeter-se a uma transformação de paradigma para que se torne um instrumento desencadeador de práticas avaliativas inclusivas, que represente um indicador de situações de desenvolvimento do educando, apontando possibilidades de mudanças

Educação \& Formação, Fortaleza, v. 3, n. 9, p. 121-140, set./dez. 2018 
e indicando meios estratégicos para a elaboração de atitudes pedagógicas (OLIVEIRA, M.; PLETSCH; OLIVEIRA, A., 2016; VALENTIM, 2011).

Alguns documentos legais e políticos orientam sobre os processos de avaliação no viés da inclusão, como a Resolução CNE/CEB no 2, de 11 de setembro de 2001, e a Política Nacional de Educação Especial na Perspectiva da Educação Inclusiva. Esses documentos orientam que a avaliação esteja em consonância com o projeto pedagógico da escola. Essa avaliação deve ser processual, formativa e dinâmica, a qual considere os conhecimentos prévios do aluno e o nível de desenvolvimento quanto às possibilidades de aprendizagem, prevalecendo nessa ação os aspectos qualitativos que indiquem ao professor as intervenções pedagógicas necessárias (BRASIL, 2001, 2008).

O ensino-aprendizagem direcionado a estudantes com deficiência está fragilizado e impotente, reflexo de políticas públicas introduzidas no sistema educacional de maneira não planejada e sem acompanhamento ou apoio especializado. As decisões governamentais não consideram as situações em que as escolas encontram-se com discursos inclusivos vazios. Dessa forma, a limitação da aluna não está restrita à sua deficiência, mas às condições às quais foi submetida pelo contexto, às lacunas educacionais vivenciadas ao longo da sua trajetória escolar, as quais foram camufladas ou até mesmo negligenciadas numa justificativa de promoção obrigatória (DINIZ, 2007; VOIVODIC, 2005).

A avaliação deve conter intencionalidade e fundamento voltados para a heterogeneidade e diferenças a fim de que proporcione benefícios que servem de subsídios para o ensino. Em suma, a avaliação para pessoas com deficiência intelectual, em especial para discentes com Síndrome de Down, requer práticas adaptativas e estratégias de ensino que contemplem suas especificidades, respeitem seus ritmos de aprendizagem e estimulem suas potencialidades para que respondam às necessidades educacionais de aprendizagem.

\section{CONSIDERAÇÕES FINAIS}

Este artigo propôs investigar a percepção dos professores sobre aspectos da inclusão escolar de alunos com Síndrome de Down (SD) e como ocorrem as adaptações curriculares no que se refere às atividades e processo avaliativo do discente com SD. A pesquisa possibilitou 
perceber que a inclusão no contexto escolar é um desafio - em virtude da existência de diferentes fatores que representam empecilhos para esse processo - e que o processo de inclusão, nos aspectos adaptações curriculares e processo avaliativo de uma aluna com SD, é difícil, principalmente pela falta de formação continuada.

O processo de avaliação constitui-se como um elemento desafiador para professores. As práticas avaliativas são desenvolvidas devido à exigência burocrática de aplicação de notas. Os professores informaram apresentar dificuldades em trabalhar com a estudante e promover um processo avaliativo que a contemplasse. As razões foram várias, entretanto a ausência de formação continuada e as limitações cognitivas da discente (correspondente às falhas educacionais ao longo da sua trajetória escolar) são as mais pertinentes e implicam significativamente esse processo.

Os dados obtidos indicaram também que a aplicação de testes ou tarefas avaliativas voltava-se para atividades básicas de pintura, recorte e colagem, as quais, por vezes, não eram associadas aos conteúdos trabalhados com os demais aprendizes, resultando em avaliações desconectadas ou até mesmo repetitivas. Ademais, em decorrência de a educanda não ser alfabetizada, atendia apenas aos requisitos de socialização, pois ela não estava ativamente participando do processo de aprendizagem, o qual é seu direito.

É importante destacar que a situação dela não é um caso particular, visto que muitos discentes com SD ou outras deficiências vivenciam essa realidade em diferentes escolas. Pode-se ressaltar que o problema não está nos professores da sala regular, na docente da sala de recurso multifuncional, na gestão ou coordenação, muito menos nos alunos, uma vez que o problema está no processo, na forma como foi introduzido e como está sendo regido nos dias atuais.

$\mathrm{Na}$ avaliação, a ação docente deve considerar o processo contínuo e qualitativo da aprendizagem, dado que a avaliação não deve ser considerada como um fato isolado das atividades diárias, mas como uma parte do processo de ensino-aprendizagem.

Esperamos que o referido estudo proporcione o desenvolvimento de reflexões a respeito de como está se constituindo no cotidiano escolar a inclusão de estudantes com SD, levando em consideração o ensino e aprendizado, bem como o processo avaliativo desses alunos, além de contribuir com discussões significativas sobre as estratégias da inclusão apresentadas por órgãos governamentais e a realidade vivenciada no dia a dia das instituições escolares.

Educação \& Formação, Fortaleza, v. 3, n. 9, p. 121-140, set./dez. 2018 


\section{REFÊRENCIAS}

BARDIN, L. Análise de conteúdo. São Paulo: 70, 2011.

BLANCO, R. A atenção à diversidade na sala de aula e as adaptações do currículo. In: COLL, C.; MARCHESI, Á.; PALACIOS, J. (Org.). Desenvolvimento psicológico e educação: transtornos do desenvolvimento e necessidades educativas especiais. 2. ed. Porto Alegre: Artmed, 2004. p. 290-308.

BRASIL. Constituição de 1988. Constituição da República Federativa do Brasil. Diário Oficial [da] República Federativa do Brasil, Poder Executivo, Brasília, DF, 5 out. 1988.

BRASIL. Declaração de Salamanca e linha de ação sobre necessidades educativas especiais. 2. ed. Brasília, DF: Corde, 1997.

BRASIL. Lei n. 9.394, de 20 de dezembro de 1996. Estabelece as Diretrizes e Bases da Educação Nacional. Diário Oficial [da] República Federativa do Brasil, Poder Executivo, Brasília, DF, 21 dez. 1996.

BRASIL. Ministério da Educação. Conselho Nacional de Educação. Resolução CNE/CEB n. 2, de 11 de setembro de 2001. Institui Diretrizes Nacionais para a Educação Especial na Educação Básica. Diário Oficial [da] República Federativa do Brasil, Poder Executivo, Brasília, DF, 14 set. 2001.

BRASIL. Ministério da Educação. Conselho Nacional de Educação. Resolução CNE/CEB n. 4, de 2 de outubro de 2009. Institui Diretrizes Operacionais para o Atendimento Educacional Especializado na Educação Básica, modalidade Educação Especial. Diário Oficial [da] República Federativa do Brasil, Poder Executivo, Brasília, DF, 5 out. 2009.

BRASIL. Ministério da Educação. Secretaria de Educação Especial. Política Nacional de Educação Especial na perspectiva da Educação Inclusiva. Brasília, DF: MEC, 2008.

CASTRO, A.; PIMENTEL, S. Atendimento educacional específico. Síndrome de Down: desafios e perspectivas na inclusão escolar. In: DÍAZ, F. et al. (Org.). Educação inclusiva, deficiência e contexto social: questões contemporâneas. Salvador: UFBA, 2009. p. 303-312.

CHRISTOFARI, A. C. Avaliação da aprendizagem: práticas e alternativas para a inclusão escolar. Inclusão: Revista de Educação Especial, Brasília, DF, v. 25, n. 44, p. 383-398, 2012.

COLL, C.; MARTÍN, E.; ONRUBIA, J. A avaliação da aprendizagem escolar: dimensões psicológicas, pedagógicas e sociais. In: COLL, C.; MARCHESI, Á.; PALACIOS, J. (Org.). Desenvolvimento psicológico e educação: psicologia da educação escolar. 2. ed. Porto Alegre: Artmed, 2004. p. 370-385.

Educação \& Formação, Fortaleza, v. 3, n. 9, p. 121-140, set./dez. 2018 
DENARI, F. Um (novo) olhar sobre a formação do professor de educação especial: da segregação à inclusão. In: RODRIGUES, D. (Org.). Inclusão e educação: doze olhares sobre a educação inclusiva. São Paulo: Summus, 2006. p. 35-63.

DINIZ, D. O que é deficiência. São Paulo: Brasiliense, 2007.

FERRAZ, C.; ARAÚJO, M.; CARREIRO, L. Inclusão de crianças com Síndrome de Down e paralisia cerebral no ensino fundamental: comparação dos relatos de mães e professores. Revista Brasileira de Educação Especial, Marília, v. 16, n. 3, p. 397-414, 2010.

FONSECA, V. Educação especial: programa de estimulação precoce - uma introdução às ideias de Freuerstein. 2. ed. Porto Alegre: Artes Médicas, 1995.

FREITAS, S. N. A formação de professores na educação inclusiva: construindo a base de todo o processo. In: RODRIGUES, D. (Org.). Inclusão e educação: doze olhares sobre a educação inclusiva. São Paulo: Summus, 2006. p. 161-181.

HEREDERO, E. S. A escola inclusiva e estratégias para fazer frente a ela: as adaptações curriculares. Acta Scientiarum Education, Maringá, v. 32, n. 2, p. 193-208, 2010.

HOFFMANN, J. M. L. Avaliação mediadora: uma relação dialógica na construção do conhecimento. Porto Alegre: Mediação, 2009.

LUCKESI, C. C. Avaliação da aprendizagem escolar: estudos e proposições. São Paulo: Cortez, 2008.

MANTOAN, M. T. E. Inclusão escolar: o que é? Por quê? Como fazer? São Paulo: Moderna, 2004.

MARCHESI, Á. A prática das escolas inclusivas. In: COLL, C.; MARCHESI, Á.; PALACIOS, J. (Org.). Desenvolvimento psicológico e educação: transtornos de desenvolvimento e necessidades educativas especiais. 3. ed. Porto Alegre: Artmed, 2004. p. 31-48.

MENDES, E. G. A radicalização do debate sobre inclusão escolar no Brasil. Revista Brasileira de Educação, Rio de Janeiro, v. 11, n. 33, p. 387-405, 2006.

MENDES, E. G. Construindo um "lócus" de pesquisas sobre inclusão escolar. In: MENDES, E. G.; ALMEIDA, M. A.; WILLIAMS, L. C. (Org.). Temas em educação especial: avanços recentes. São Carlos: UFSCAR, 2004. p. 221-230.

MITTLER, P. Educação inclusiva: contextos sociais. Porto Alegre: Artmed, 2003.

NUNES, C.; MADUREIRA, I. Desenho universal para a aprendizagem: construindo práticas pedagógicas inclusivas. Revista da Investigação às Práticas, Lisboa, v. 5, n. 2, p. 126-143, 2015.

Educação \& Formação, Fortaleza, v. 3, n. 9, p. 121-140, set./dez. 2018

DOI: https://doi.org/10.25053/redufor.v3i9.859

http://seer.uece.br/redufor 
OLIVEIRA, A.; CAMPOS, T. Avaliação em educação especial: o ponto de vista do professor de alunos com deficiência. Revista Estudos em Avaliação Educacional, São Paulo, v. 16, n. 31, p. 5178, 2005.

OLIVEIRA, M.; PLETSCH, M. A avaliação da aprendizagem de alunos com deficiência intelectual em tempos de educação inclusiva. In: SEMINÁRIO INTERNACIONAL DE INCLUSÃO ESCOLAR: PRÁTICAS EM DIÁLOGO, 1., 2014, Rio de Janeiro. Anais... Rio de Janeiro: UERJ, 2014. p. 1-10.

OLIVEIRA, M.; PLETSCH, M.; OLIVEIRA, A. A. Contribuições da avaliação mediada para a escolarização de alunos com deficiência intelectual. Revista Teias, Rio de Janeiro, v. 17, n. 46, p. 72-79, 2016.

OLIVEIRA, M.; SILVA, M. Inclusão escolar de crianças com Síndrome de Down: uma análise à luz da teoria sócio-histórica. Pracs: Revista de Humanidades do Curso de Ciências Sociais da Unifap, Macapá, v. 3, n. 3, p. 93-108, 2010.

PACHECO, W.; OLIVEIRA, M. Aprendizagem e desenvolvimento da criança com Síndrome de Down: representações sociais de mães e professoras. Revista Ciências \& Cognição, Rio de Janeiro, v. 16, n. 3, p. 2-14, 2011.

PALACIOS, J. Introdução à psicologia evolutiva: história, conceitos básicos e metodologia. In: COLL, C.; PALACIOS, J.; MARCHESI, Á. (Org.). Desenvolvimento psicológico e educação. Porto Alegre: Artes Médicas, 1995. p. 9-26.

PIMENTEL, S. C. Conviver com a Síndrome de Down em escola inclusiva: mediação pedagógica e formação de conceitos. Petrópolis: Vozes, 2012.

PLETSCH, M. D. A dialética da inclusão/exclusão nas políticas educacionais para pessoas com deficiências: um balanço do governo Lula (2003-2010). Revista Teias, Rio de Janeiro, v. 12, n. 24, p. 39-55, 2011.

PLETSCH, M. D.; SOUZA, F. F. D.; ORLEANS, L. F. A diferenciação curricular e o desenho universal na aprendizagem como princípios para a inclusão escolar. Revista Educação e Cultura Contemporânea, Rio de Janeiro, v. 14, n. 35, p. 264-281, 2017.

ROPOLI, E. et al. A educação especial na perspectiva da inclusão escolar: a escola comum inclusiva. Brasília. DF: MEC; Fortaleza: UFC, 2010.

SEVERINO, A. Metodologia do trabalho científico. São Paulo: Cortez, 2007.

SOUSA, N. M. F. R. A pessoa com deficiência física: representações sociais de alunos usuários de cadeira de rodas sobre a escolarização e as implicações no processo formativo. Tese (Doutorado em Educação) - Programa de Pós-Graduação em Educação, Universidade Federal do Pará, Belém, 2015.

Educação \& Formação, Fortaleza, v. 3, n. 9, p. 121-140, set./dez. 2018

DOI: https://doi.org/10.25053/redufor.v3i9.859

http://seer.uece.br/redufor 
SOUZA, A. M. L.; MACEDO, M. C. S. R. Avaliação da aprendizagem e inclusão escolar: a singularidade a serviço da comunidade. Revista Semestral da Associação Brasileira de Psicologia Escolar e Educacional, São Paulo, v. 16, n. 2, p. 283-290, 2012.

SOUSA, L. P. F. Orquestrar a gestão escolar para respostas educativas na diversidade. 2007. 113 f. Dissertação (Mestrado em Educação) - Programa de Pós-Graduação em Educação, Universidade do Estado do Rio de Janeiro, Rio de Janeiro, 2007.

TARDIF, M. Saberes docentes e formação profissional. Petrópolis: Vozes, 2002.

TRENTIN, D. G. Análise dos caminhos isotrópicos adotados por pessoas com deficiência visual em um curso de educação a distância na perspectiva inclusiva. 2013. 142 f. Dissertação (Mestrado em Educação) - Programa de Pós-Graduação em Educação, Universidade Estadual Paulista, Presidente Prudente, 2013.

UNESCO. Declaração mundial sobre educação para todos: satisfação das necessidades básicas de aprendizagem. Jomtien: Unesco, 1990.

VALENTIM, F. O. D. Inclusão de alunos com deficiência intelectual: considerações sobre avaliação da aprendizagem escolar. 2011. 143 f. Dissertação (Mestrado em Educação) - Programa de Pós-Graduação em Educação, Universidade Estadual Paulista, Marília, 2011.

VALENTIM, F. O. D.; OLIVEIRA, A. Avaliação da aprendizagem e deficiência intelectual na perspectiva de professores do ensino comum. Revista Diálogo Educacional, Curitiba, v. 13, n. 40, p. 851-871, 2013.

VOIVODIC, M. A. Inclusão escolar de crianças com Síndrome de Down. Petrópolis: Vozes, 2005.

Recebido em 17 de novembro de 2017.

Aceito em 05 de agosto de 2018.

Educação \& Formação, Fortaleza, v. 3, n. 9, p. 121-140, set./dez. 2018

DOI: https://doi.org/10.25053/redufor.v3i9.859

http://seer.uece.br/redufor 